\title{
Base pair interactions and hybridization isotherms of matched and mismatched oligonucleotide probes on microarrays
}

\author{
Hans Binder*, Stephan Preibisch, Toralf Kirsten \\ Interdisciplinary Centre for Bioinformatics, University of Leipzig \\ * corresponding author: Interdisciplinary Centre for Bioinformatics of Leipzig University, D-4107 \\ Leipzig, Haertelstr. 16-18, binder@izbi.uni-leipzig.de, fax: ++49-341-97-16679
}

\section{Supplementary Material}

\section{S1: Single base contribution of fluorescence emission}

The length of the RNA fragments, $\mathrm{N}_{\mathrm{b}}{ }^{\mathrm{RNA}}$, typically exceeds the length of the 25 meric oligomer probes. Consequently also labelled bases which dangle outside of the probe/target duplex potentially contribute to the measured fluorescence intensity in addition to labels attached to the 25meric target region. Let us denote the number of bases outside of the respective 25 meric duplex by $\mathrm{N}_{\mathrm{b}}{ }^{\text {out }}$ for a RNA fragment of total length $\mathrm{N}_{\mathrm{b}}{ }^{\mathrm{RNA}}=\mathrm{N}_{\mathrm{b}}+\mathrm{N}_{\mathrm{b}}{ }^{\text {out }}$. The respective number of labelled bases inside and outside of the 25 mer is $\mathrm{N}_{\mathrm{p}}^{\mathrm{F} \text {,in }}\left(\xi^{\mathrm{T}}\right)$ and $\mathrm{N}_{\mathrm{p}}^{\mathrm{F} \text {,out }}\left(\xi^{\mathrm{T}, \text { out }}\right)$, respectively, where $\xi^{\mathrm{T}, \text { out }}$ is the subsequence of the target RNA exceeding the probe on both sides. The fluorescence intensity of a RNA fragment is related to the number of labelled $\mathrm{c}^{*}$ and $\mathrm{u}^{*}$, which is given by the number of complementary $\mathrm{G}$ and $\mathrm{A}$ of the target gene according to $\mathrm{N}_{\mathrm{p}}^{\mathrm{F}, \mathrm{S}}=\mathrm{N}_{\mathrm{p}}^{\mathrm{F} \text {,in }}\left(\xi^{\mathrm{T}}\right)+\mathrm{N}_{\mathrm{p}}^{\mathrm{F} \text {,out }}\left(\xi^{\mathrm{T}, \text { out }}\right)=\mathrm{N}_{\mathrm{p}}^{\mathrm{u}^{*}}\left(\xi^{\mathrm{T}}+\xi^{\mathrm{T}, \text { out }}\right)+\mathrm{N}_{\mathrm{p}}^{\mathrm{c}^{*}}\left(\xi^{\mathrm{T}}+\xi^{\mathrm{T}, \text { out }}\right)=\mathrm{N}_{\mathrm{p}}^{\mathrm{A}}\left(\xi^{\mathrm{P}}+\xi^{\mathrm{P}, \text { out }}\right)+\mathrm{N}_{\mathrm{p}}^{\mathrm{G}}\left(\xi^{\mathrm{P}}+\xi^{\mathrm{P} \text {,out }}\right)$

if one assumes exclusively WC pairings. The contribution to the sensitivity of a selected probe owing to the number of potentially labelled bases per target, $\mathrm{N}_{\mathrm{p}}^{\mathrm{F}, \mathrm{S}}$, is (see Eqs. 1 and 7)

$$
\begin{aligned}
& \mathrm{Y}_{\mathrm{p}}^{\mathrm{P}, \mathrm{F}} \equiv \log \mathrm{N}_{\mathrm{p}}^{\mathrm{F}}-\left\langle\log \mathrm{N}_{\mathrm{p}}^{\mathrm{F}}\right\rangle_{\text {set }}=\Delta_{\mathrm{p}}^{\mathrm{F}} \cdot\left[\sum_{\mathrm{k}=1}^{\mathrm{N}_{\mathrm{b}}} \sum_{\mathrm{B}=\mathrm{A}, \mathrm{G}}\left(\delta\left(\mathrm{B}, \xi_{\mathrm{k}}^{\mathrm{P}}\right)-\mathrm{f}_{\mathrm{k}}^{\text {set }}(\mathrm{B})\right)-\sum_{\mathrm{k}=1}^{\mathrm{N}_{\mathrm{b}}} \sum_{\mathrm{B}=\mathrm{T}, \mathrm{C}}\left(\delta\left(\mathrm{B}, \xi_{\mathrm{k}}^{\mathrm{P}}\right)-\mathrm{f}_{\mathrm{k}}^{\text {set }}(\mathrm{B})\right)\right] \\
& \text { with } \quad \Delta_{\mathrm{p}}^{\mathrm{F}}=\frac{\log \mathrm{N}_{\mathrm{p}}^{\mathrm{F}}-\left\langle\log \mathrm{N}_{\mathrm{p}}^{\mathrm{F}}\right\rangle_{\text {set }}}{\delta \mathrm{N}_{\mathrm{p}}^{\mathrm{F} \text {,in }}} \text { and } \delta \mathrm{N}_{\mathrm{p}}^{\mathrm{F} \text {,in }}=\mathrm{N}_{\mathrm{p}}^{\mathrm{F} \text {,in }}-\left\langle\mathrm{N}_{\mathrm{p}}^{\mathrm{F} \text {,in }}\right\rangle_{\text {set }}=\sum_{\mathrm{k}=1}^{\mathrm{N}_{\mathrm{b}}} \sum_{\mathrm{B}=\mathrm{A}, \mathrm{T}, \mathrm{G}, \mathrm{C}}\left(\delta\left(\mathrm{B}, \xi_{\mathrm{k}}^{\mathrm{P}}\right)-\mathrm{f}_{\mathrm{k}}^{\text {set }}(\mathrm{B})\right)
\end{aligned}
$$

where averaging was performed over the probe set $(\Sigma \equiv$ set).

The coefficient $\Delta_{\mathrm{p}}{ }^{\mathrm{F}}$ specifies the contribution of fluorescence labelling per potentially labelled base in the considered target sequence of length $\mathrm{N}_{\mathrm{b}}$. Effectively each labelled base pair increases and each nonlabelled pair decreases the sensitivity by $\Delta_{\mathrm{p}}^{\mathrm{F}}$. With $\delta \mathrm{N}_{\mathrm{p}}^{\mathrm{F}}=\delta \mathrm{N}_{\mathrm{p}}^{\mathrm{F} \text {.in }}+\delta \mathrm{N}_{\mathrm{p}}^{\mathrm{F}, \text { out }}\left(\delta \mathrm{N}_{\mathrm{p}}^{\mathrm{F}, \mathrm{i}}=\mathrm{N}_{\mathrm{p}}^{\mathrm{F}, \mathrm{i}}\right.$ - 
$\left\langle\mathrm{N}_{\mathrm{p}}^{\mathrm{F}, \mathrm{i}}>_{\text {set }}, \mathrm{i}=\right.$ in, out) and $\left\langle\delta \mathrm{N}^{\mathrm{F}}>_{\text {set }}=0\right.$ one obtains the following approximation for $\Delta_{\mathrm{p}}^{\mathrm{F}}$ in the limit of small $\delta \mathrm{N}_{\mathrm{p}}{ }^{\mathrm{F}} /<\mathrm{N}_{\mathrm{p}}{ }^{\mathrm{F}}>_{\text {set }}<<1$, which is justified for sequence lengths $\mathrm{N}_{\mathrm{b}}{ }^{\mathrm{RNA}}>20$,

$\Delta_{\mathrm{p}}^{\mathrm{F}}=\left[\log \left(1+\delta \mathrm{N}_{\mathrm{p}}^{\mathrm{F}} /<\mathrm{N}_{\mathrm{p}}{ }^{\mathrm{F}}>_{\text {set }}\right)-<\log \left(1+\delta \mathrm{N}_{\mathrm{p}}{ }^{\mathrm{F}} /<\mathrm{N}_{\mathrm{p}}{ }^{\mathrm{F}}>_{\text {set }}\right)>_{\text {set }}\right] / \delta \mathrm{N}_{\mathrm{p}}^{\mathrm{F}}$,in

$\approx\left(\ln 10 \cdot \delta \mathrm{N}_{\mathrm{p}}^{\mathrm{F}, \text { in }} \cdot<\mathrm{N}_{\mathrm{p}}{ }^{\mathrm{F}}>_{\text {set }}\right)^{-1}\left(\delta \mathrm{N}_{\mathrm{p}}^{\mathrm{F}}-<\delta \mathrm{N}^{\mathrm{F}}>\right)=\left(1+\delta \mathrm{N}_{\mathrm{p}}^{\mathrm{F}, \text { out }} / \delta \mathrm{N}_{\mathrm{p}}^{\mathrm{F}, \text { in }}\right) /\left(\ln 10<\mathrm{N}_{\mathrm{p}}{ }^{\mathrm{F}}>_{\text {set }}\right)$.

The binominal distribution $B\left(N^{F}, N_{b}^{\text {tot }}, p\right)=\left(\begin{array}{c}N_{b}^{\text {tot }} \\ N^{F}\end{array}\right) p^{N^{F}}(1-p)^{N_{b}^{\text {vet }}-N^{F}}$ specifies the probability to find $N_{p}{ }^{F}$ potentially labelled nucleotides among a total sequence length of the target fragment of $\mathrm{N}_{\mathrm{b}}{ }^{\mathrm{RNA}}$ nucleotides where $\mathrm{p} \approx 0.5$ is the probability for a uracyl or a cytosine at any position of the target sequence. After substitution of the set average by the overall mean of the number of labels per target by $\left\langle\mathrm{N}_{\mathrm{p}}{ }^{\mathrm{F}}\right\rangle_{\text {set }} \approx\left\langle\mathrm{N}_{\mathrm{p}}{ }^{\mathrm{F}}\right\rangle_{\text {binom }}=\mathrm{p} \cdot \mathrm{N}_{\mathrm{b}}{ }^{\mathrm{RNA}}$ one gets the relative fluorescence contribution per sequence position

$\Delta_{\mathrm{p}}^{\mathrm{F}} \approx\left(1+\frac{\delta \mathrm{N}_{\mathrm{p}}^{\mathrm{F}, \text { out }}}{\delta \mathrm{N}_{\mathrm{p}}^{\mathrm{F} \text {,in }}}\right) \cdot \Delta_{0}^{\mathrm{F}} \quad$ with $\quad \Delta_{0}^{\mathrm{F}}=\left(\ln 10 \cdot \mathrm{p} \cdot \mathrm{N}_{\mathrm{b}}^{\mathrm{RNA}}\right)^{-1} \approx \frac{2}{\ln 10 \cdot \mathrm{N}_{\mathrm{b}}^{\mathrm{RNA}}}$

Its mean value,

$\Delta^{\mathrm{F}} \equiv\left\langle\Delta_{\mathrm{p}}^{\mathrm{F}}\right\rangle_{\text {chip }} \approx\left(1+\sqrt{\frac{\mathrm{N}_{\mathrm{b}}^{\mathrm{out}}}{\mathrm{N}_{\mathrm{b}}}}\right) \cdot \Delta_{0}^{\mathrm{F}}=\left(1+\sqrt{\frac{\mathrm{N}_{\mathrm{b}}^{\mathrm{RNA}}}{\mathrm{N}_{\mathrm{b}}}-1}\right) \cdot \Delta_{0}^{\mathrm{F}}$

provides the average contribution per considered base within a probe sequence of lenth $\mathrm{N}_{b}$ as a function of the total length of the RNA fragment, $\mathrm{N}_{\mathrm{b}}{ }^{\mathrm{RNA}}$. The mean incremental contributions are approximated in Eq. A3 by the standard deviation of the binominal distribution according to $<\delta \mathrm{N}>_{\text {set }} \approx \mathrm{p} \cdot \mathrm{N}^{0.5}$.

Bases in the probe sequence referring $(B=A, G)$ and not-referring $(B=T, C)$ to labels in the complementary target sequence add and subtract the constant contribution $\Delta^{\mathrm{F}}$ to the sensitivity, respectively. 


\section{S2: Signal and sensitivity error of single Affymetrix GeneChips}

The weighting factor for the least squares fits of the positional dependent sensitivity models is given by the variance of the experimental sensitivity data, $\omega_{\mathrm{p}}^{\mathrm{P}}{ }^{2} \approx \operatorname{var}\left(\mathrm{Y}_{\mathrm{p}}^{\mathrm{P}}\right){ }^{1}$. It can be estimated for each probe from chip replicates using standard error analysis. The SB sensitivity contributions are partly obtained from least square fits of the sensitivity data of single chips. We therefore developed a method, which estimates $\operatorname{var}\left(\mathrm{Y}_{\mathrm{p}}^{\mathrm{P}}\right)$ for each individual chip using selected probe intensities.

The variance of the sensitivity can be directly related to the variance of the respective signal intensity according to Eq. 6, $\operatorname{var}\left(\mathrm{Y}_{\mathrm{p}}^{\mathrm{P}}\right) \approx \operatorname{var}\left(\log \left(\mathrm{I}_{\mathrm{p}}^{\mathrm{P}}\right)\right)+\operatorname{var}\left(<\log \left(\mathrm{I}_{\mathrm{p}}^{\mathrm{P}}\right)>\right) \approx \operatorname{var}\left(\log \left(\mathrm{I}_{\mathrm{p}}{ }^{\mathrm{P}}\right)\right)\left(1+\left(\mathrm{N}_{\text {probe }}-1\right)^{-1}\right) \approx$ $\operatorname{var}\left(\log \left(\mathrm{I}_{\mathrm{p}}^{\mathrm{P}}\right)\right)$ where $\mathrm{N}_{\text {probe }}=11-20$ is the number of probes per probe set. For the estimation of the chip-specific value of $\omega_{\mathrm{p}}^{\mathrm{P}}{ }^{2}$ we make use of the fact that a considerable number of PM and MM probes are present as replicates on each Affymetrix ${ }^{\odot}$ chip. We identified repeated probes by comparison of all sequences present on the chip. For example, the human HG U133 chip contains 3463 probes in duplicate (2x), 725 in triplicate (3x), 186 fourfold (4x), 77 fivefold (5x), 37 sixfold (6x), 7 sevenfold $(7 \mathrm{x}), 2$ ninefold $(9 \mathrm{x})$ and one each for 12x, 16x and 20x. We calculated the variance, $\operatorname{var}_{\exp }\left(\log \left(\mathrm{I}_{\mathrm{p}}^{\mathrm{P}}\right)^{\mathrm{x}}\right.$ $(\mathrm{P}=\mathrm{PM}, \mathrm{MM})$ and log-averaged mean intensity, $\left\langle\mathrm{I}_{\mathrm{p}}{ }^{\mathrm{P}}>=\exp \left(<\ln \mathrm{I}_{\mathrm{p}}{ }^{\mathrm{P}}>_{\text {replicate }}\right)\right.$, for each of these groups of replicates for a selected chip.

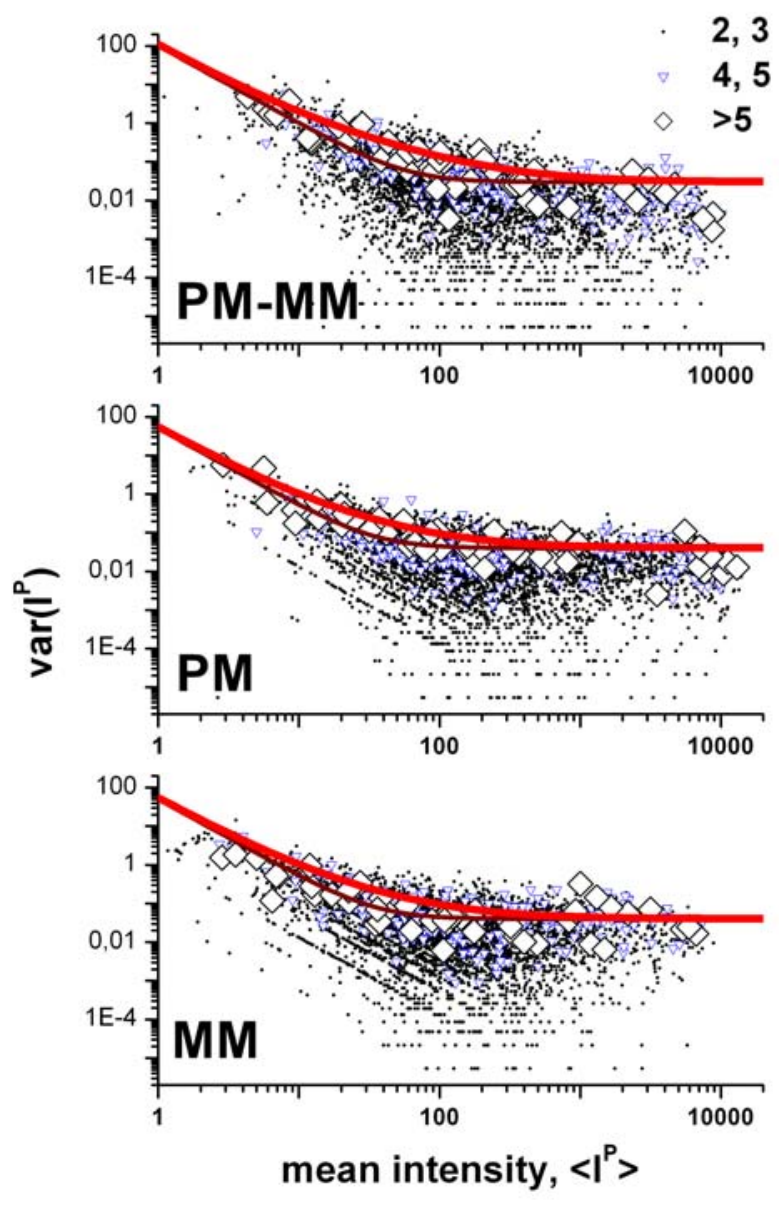

Figure S2: Log-log plot of the variance of the intensities of replicate PM and MM probes present on a HG U133 chip as a function of the mean intensity $<\mathrm{I}^{\mathrm{P}}>$ averaged over probes present in duplicate and triplicate (see legend in the Figure: 2,3...small points), four- and fivefold $(4,5 \ldots$ small triangles) and more than fivefold ( $>5 \ldots$.rhombes $)$. The lines are calculated according to the error model (Eq. A5) with $\mathrm{a} / \mathrm{b} / \mathrm{c}=0.04 / 5 / 50$ (thick line) and 0.04/0/50 (thin line) for $\mathrm{P}=\mathrm{PM}$ and MM. The panel above shows the respective analysis of log-intensity differences, PM-MM. In this case the variance is given by $\operatorname{var}\left(\log \mathrm{I}^{\mathrm{PM}-}\right.$ $\left.{ }^{\mathrm{MM}}\right)=\operatorname{var}\left(\log \mathrm{I}^{\mathrm{PM}}-\log \mathrm{I}^{\mathrm{MM}}\right)$ and the squared mean intensity by $<\mathrm{I}^{\mathrm{PM}+\mathrm{MM}}>^{2}=<\mathrm{I}^{\mathrm{PM}} \cdot \mathrm{I}^{\mathrm{MM}}>$ ${ }^{1}=\exp \left[<\ln \left(\mathrm{I}^{\mathrm{PM}}+\mathrm{I}^{\mathrm{MM}}\right)>\right.$. The thick and thin lines are calculated with $\mathrm{a} / \mathrm{b} / \mathrm{c}=0.03 / 10 / 100$ and $0.03 / 0 / 100$, respectively. 
The uncorrected signal intensity can be rewritten according to Eq. 1 (in the original article) in a simplified version as $\mathrm{I}_{\mathrm{p}}{ }^{\mathrm{P}} * \approx\left(<\mathrm{F}_{\text {chip }} \cdot \mathrm{N}^{\mathrm{F}} \cdot \mathrm{c}_{\mathrm{RNA}}>+\mathrm{e}_{\mathrm{F}}\right) \cdot \exp \left[\left(<\ln _{\mathrm{p}}{ }^{\mathrm{P}}>+\mathrm{e}_{\mathrm{G}}\right)\right]+\left(<\beta_{\mathrm{p}}{ }^{\mathrm{P}}>+\mathrm{e}_{\mathrm{B}}\right)$ where the angular brackets, $\langle\ldots\rangle$, denote means over replicated probes. The $e_{i}(i=F, G, B)$ are error terms and $\beta_{p}{ }^{P}$ is the optical background of each probe, which is not related to hybridization. With $<\mathrm{I}_{\mathrm{p}}{ }^{\mathrm{P}}>\approx<\mathrm{F}_{\text {chip }} \cdot \mathrm{N}^{\mathrm{F}} \cdot \mathrm{c}_{\mathrm{RNA}} \cdot \mathrm{K}_{\mathrm{p}}{ }^{\mathrm{b}}>$ one obtains the background-corrected intensity

$\mathrm{I}_{\mathrm{p}}{ }^{\mathrm{P}} \approx \mathrm{I}_{\mathrm{p}}{ }^{\mathrm{P}}{ }^{*}-<\beta_{\mathrm{p}}{ }^{\mathrm{P}}>\approx\left(<\mathrm{I}_{\mathrm{p}}{ }^{\mathrm{P}}>+\mathrm{e}_{\mathrm{F}}\right) \cdot \exp \left(\mathrm{e}_{\mathrm{G}}\right)+\mathrm{e}_{\mathrm{B}}$

The constant $\mathrm{F}_{\text {chip }}$ depends on the yield of labelling (fraction of labelled uracyls and cytosines), on the number of oligos per spot and on the efficiency of the detector and of the imaging system (see ref. ${ }^{2}$ for details). Consequently the first error term, $e_{\mathrm{F}}$, considers effects such as variations of the labelling efficiency, of the number of oligos per probe spot and of their density, of the RNA concentration and the noise of the detector and of the imaging system. The exponential term, $\varepsilon_{\mathrm{G}}$, can be rationalized as the error of the free energy of duplex formation, $\Delta \mathrm{G}_{\mathrm{p}}{ }^{\mathrm{b}} \propto-\operatorname{lnK}_{\mathrm{p}}{ }^{\mathrm{P}}$, which is related, e.g., to incorrect sequences of individual oligos in each probe spot due to imperfect synthesis and/or to non-equilibrium effects of target binding. The last error, $\mathrm{e}_{\mathrm{B}}$, considers the noise of the detector and of the imaging system in the absence of hybridization.

The variance of $\log$ transformed and background corrected signal intensity is described to a good approximation by $\operatorname{var}_{\text {mod }}\left[\log \left(\mathrm{I}_{\mathrm{p}}^{\mathrm{P}}\right)\right] \approx \mathrm{a}+\mathrm{c} /\left(<\mathrm{I}_{\mathrm{p}}{ }^{\mathrm{P}}>\right)^{2}$ with $\mathrm{a} \approx \mathrm{s}_{\mathrm{G}}{ }^{2} /(\ln 10)^{2}$ and $\mathrm{c} \approx\left(\mathrm{s}_{\mathrm{F}}{ }^{2}+\mathrm{s}_{\mathrm{B}}{ }^{2}\right)$ if one assumes exclusively normally distributed error terms with mean 0 and variance $\mathrm{s}_{\mathrm{i}}{ }^{2}(\mathrm{i}=\mathrm{F}, \mathrm{G}, \mathrm{B})$. This result agrees with a previously proposed error model of microarray intensity data ${ }^{3}$.

Figure S2 compares experimental and theoretical variance data of PM and MM intensities and of their difference in a double-logarithmic scale. The model curves systematically underestimate the experimental variance data in the intermediate intensity range, $100<\mathrm{I}^{\mathrm{P}}<1000$ (see thin lines in Fig. $\mathrm{S} 2$ ). Considerable better agreement was achieved if one adds a term $\sim<\mathrm{I}^{\mathrm{P}}>^{-1}$ according to (see thick lines in Fig. 13)

$$
\operatorname{var}_{\text {mod }}\left(\log \mathrm{I}_{\mathrm{p}}^{\mathrm{P}}\right) \approx \mathrm{a}+\frac{\mathrm{b}}{\left\langle\mathrm{I}_{\mathrm{p}}{ }^{\mathrm{P}}\right\rangle}+\frac{\mathrm{c}}{\left\langle\mathrm{I}_{\mathrm{p}}{ }^{\mathrm{P}}\right\rangle^{2}}
$$

The additional term can be tentatively rationalized as non-Gaussian error terms, which contribute to $\mathrm{e}_{\mathrm{F}}$. Here we use Eq. A5 without further specification as an empirical measure to estimate the weighting factor in the sum of squared residuals in the least squares fits as a function of the signal intensity.

The analysis of the intensity difference, $\operatorname{var}\left(\log \mathrm{I}^{\mathrm{PM}}-\log \mathrm{I}^{\mathrm{MM}}\right)$, as a function of $<\mathrm{I}^{\mathrm{PM}} \cdot \mathrm{I}^{\mathrm{MM}}>^{-1}=\exp [-$ $<\ln \left(\mathrm{I}^{\mathrm{PM}}+\mathrm{I}^{\mathrm{MM}}\right)>$ provides similar plots as that for PM and MM (Fig. S2, panel above). The respective background error is however increased whereas the signal error decreases compared with the respective error data of PM and MM probes. This result is compatible with a uncorrelated background noise of PM and MM intensities. In this case one expects for the background error of the logdifference of $\mathrm{PM}$ and $\mathrm{MM}$ probes a standard deviation of $\mathrm{s}_{\mathrm{B}}{ }^{2}(\mathrm{PM}-\mathrm{MM}) \approx \mathrm{S}_{\mathrm{B}}{ }^{2}(\mathrm{PM})+\mathrm{s}_{\mathrm{B}}{ }^{2}(\mathrm{MM}) \approx$ $2 \mathrm{~s}_{\mathrm{B}}{ }^{2}(\mathrm{PM})$, where the arguments $\mathrm{PM}$ and MM refer to the log-transformed intensities of the respective probes. On the other hand, the signal error term, "a", of $\operatorname{var}\left(\log \mathrm{I}^{\mathrm{PM}}-\log \mathrm{I}^{\mathrm{MM}}\right)$ slightly reduces when 
compared with that of the individual PM and MM probes. This result can be explained with correlations between the PM and MM intensities, which are discussed in the paper.

\section{References}

(1) Bevington, P. R. Data Reduction and Error Analysis for the Physical Sciences; McGraw-Hill: New York, 1969.

(2) Binder, H.; Preibisch, S. Biophys. J. 2005, 89, 337.

(3) Rocke, D. M.; Durbin, B. J. Comput. Biol. 2001, 8, 557. 


\section{S3: Overview of SB free energy parameters of DNA/RNA duolexes}

Relations between the positional dependent SB free energy and fluorescence contributions of WatsonCrick (WC) and self complementary (SC) pairings in DNA/RNA oligonucleotide duplexes of the PM and MM microarray probes upon-specific (S) and non-specific (NS) hybridization ${ }^{\text {a }}$

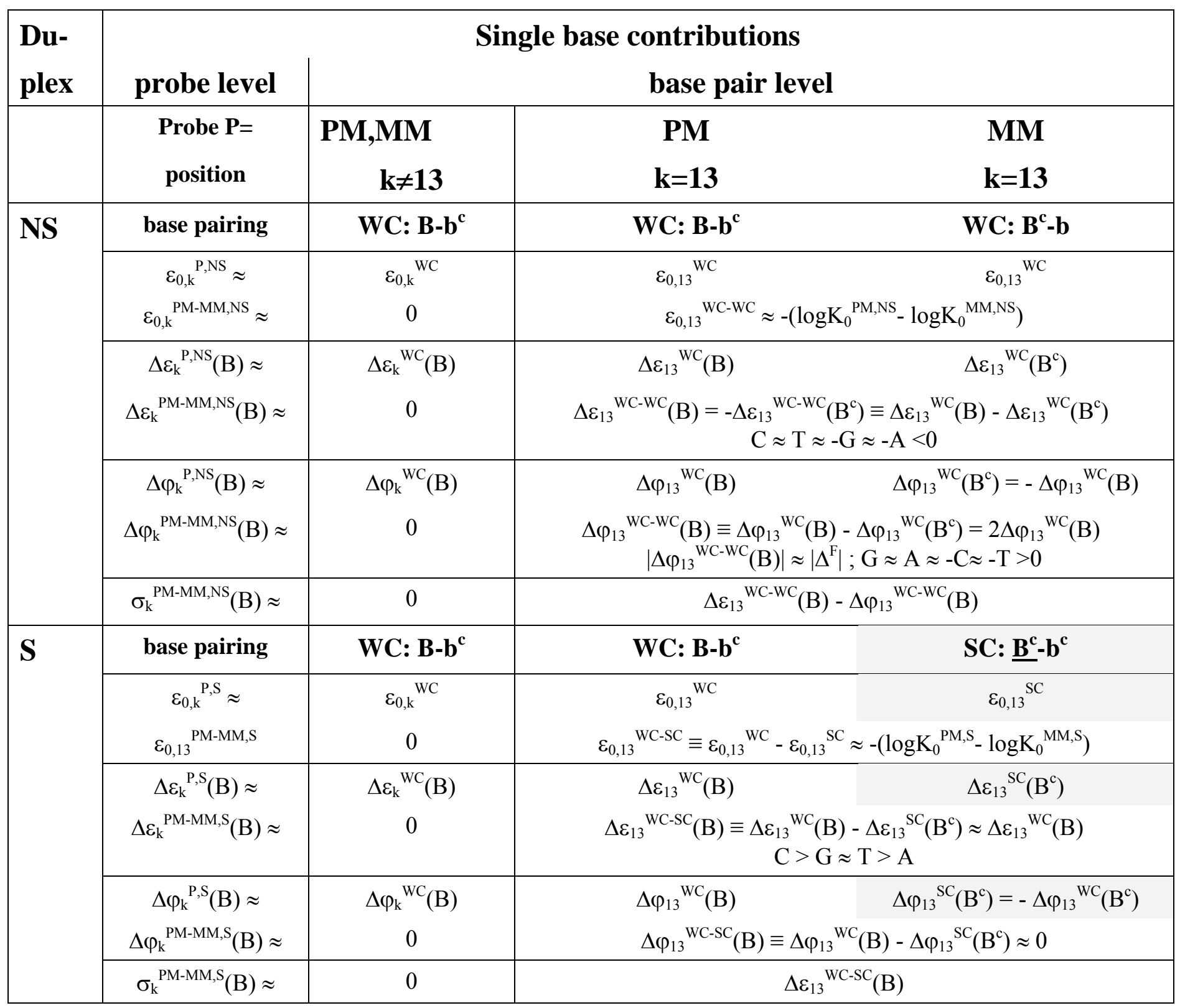

Single base related free energy $(\varepsilon)$, fluorescence $(\varphi)$ and sensitivity $(\sigma)$ contributions to the probe intensities. The index $\mathrm{k}$ indicates the position of base $\mathrm{B}=\mathrm{A}, \mathrm{T}, \mathrm{G}, \mathrm{C}$ along the probe sequence. $\mathrm{k}=13$ refers to the middle base whereas $k \neq 13$ refers to all positions outside the middle base. The superscript " $\mathrm{c}$ " denotes the complementary base, e.g., for $\mathrm{B}=\mathrm{A}$ one gets of $\mathrm{B}^{\mathrm{c}}=\mathrm{T}$. Single See text. 